\title{
Twin-twin transfusion syndrome: neurodevelopment of infants treated with laser surgery
}

\author{
Síndrome de transfusão feto-fetal: neurodesenvolvimento de lactentes tratados com \\ cirurgia a laser
}

\author{
Denise Campos' , Amabile V. Arias', Thatiane M. Campos-Zanelli', Daniela S. Souza', Orlando G. dos Santos \\ Neto², Cleisson Fabio A. Peralta², Marilisa M. Guerreiro'
}

\begin{abstract}
Objective: To assess the neurodevelopmental functions of survivors of twin-twin transfusion syndrome (TTTS) treated by fetoscopic laser coagulation (FLC), during the first year of life, comparing them to a control group; and to verify the influence of specific variables on neurodevelopment. Method: This was a prospective, longitudinal study. The sample comprised 33 monochorionic diamniotic twins who underwent FLC for treatment of TTTS and 22 full-term infants of single-fetus pregnancies. Bayley Scales of Infant and Toddler Development Screening Test were used for evaluation. Prenatal, perinatal and postnatal information were obtained. Results: There was an increased frequency of infants in the TTTS group with inadequate performance compared to the control group. The identified variables (fetal donor, low economic income and cardiorespiratory disease) negatively impacted expressive communication and fine motor skills. Conclusion: Although through follow-up is recommended in all TTTS survivors, particular attention is required for the high-risk group as defined in this study.
\end{abstract}

Keywords: diseases in twins; fetofetal transfusion; child development; risk factors.

\section{RESUMO}

Objetivo: Avaliar o desenvolvimento neurológico de sobreviventes da sindrome de transfusão feto-fetal (STFF) submetidos à coagulação a laser por fetoscopia (CLF), durante o primeiro ano de vida, comparando estes ao grupo controle; e verificar a influência de variáveis específicas no desenvolvimento. Método: Tratou-se de estudo prospectivo, longitudinal. A amostra foi composta por 33 gêmeos diamnióticos monocoriônicos submetidos à CLF para tratamento da STFFe 22 lactentes a termo de gestação única. Bayley Scales of Infant and Toddler Development Screening Test foram utilizadas para avaliação. Informações pré-natal, perinatal e pós-natal foram coletadas. Resultados: Houve maior número de lactentes com desempenho inadequado no grupo STFF do que no controle. As variáveis identificadas (feto doador, baixa renda econômica e doença cárdio-respiratória) influenciaram negativamente a comunicação expressiva e as habilidades motoras finas. Conclusão: Embora o acompanhamento seja recomendado para todos lactentes com STFF, especial atenção deve ser dada àqueles que apresentam fatores de risco.

Palavras-chave: doenças em gêmeos; transfusão feto-fetal; desenvolvimento infantil; fatores de risco.

Twin-twin transfusion syndrome (TTTS) is a serious condition that affects $9 \%$ to $15 \%$ of all monochorionic diamniotic twin pregnancies ${ }^{1}$, and typically develops between 15 and 26 weeks of gestation ${ }^{2}$. The syndrome is characterized by an unbalanced transfusion of blood across placental vascular anastomoses from one twin (donor) to the other (recipient $)^{2,3,4}$. Because of abnormal placental anastomoses, the donor pumps blood into the recipient. The donor twin becomes hypovolemic, with resultant oliguria, oligohydramnios, and sometimes growth restriction. The recipient becomes hypervolemic, with polyuria, polyhydramnios, and cardiac dysfunction ${ }^{3}$.

Untreated, the risk of fetal death is approximately $90 \%^{3,4}$. The optimal treatment for TTTS is fetoscopic laser coagulation (FLC) of placental anastomoses, which has led to improved single and dual twin survival. With this improvement in survival, there is a concern regarding risk factors to the neonatal neurologic status and later neurodevelopmental outcome $e^{5,6}$.

Fetoscopic laser coagulation interrupts the blood flow between the fetuses and reducing the potential for major

1 Universidade Estadual de Campinas, Departamento de Neurologia e Centro de Investigação em Pediatria, Campinas SP, Brazil;

2Universidade Estadual de Campinas, Departamento de Obstetrícia e Ginecologia e Hospital da Mulher Prof. Dr. José Aristodemo Pinotti, Campinas SP, Brazil.

Correspondence: Denise Campos; Departamento de Neurologia, Universidade Estadual de Campinas; Rua Tessália Vieira de Camargo, 126; $13083-887$

Campinas SP, Brasil; E-mail: denise.campos@gmail.com

Conflict of interest: There is no conflict of interest to declare.

Received 14 July 2015; Received in final form 18 November 2015; Accepted 30 November 2015. 
neurodevelopmental disability in survivors ${ }^{7,8}$. Nevertheless, neurologic morbidity rates after antenatal treatment remain high $(15 \% \text { to } 26 \%)^{1}$. It is important to emphasize that information about the effects of TTTS in the infant development are still scarce, and risk factors associated with neurodevelopment impairment have not yet been established ${ }^{1,7,9,10}$.

With this in mind, the questions posed by the present study were: what is the developmental profile of infants who suffered from TTTS? What are the factors that influenced the infant development? In order to answer these questions, the present study aimed to assess the neurodevelopmental functions (cognition, language and motor function) of survivors of TTTS treated by FLC during the first year of life, comparing them to a control group ( full-term infants of single-fetus pregnancies); and to verify the influence of specific variables on neurodevelopment.

It was hypothesized that detailed assessment during the first months of life would provide important information for identifying early developmental disadvantages in TTTS infants. Considering that there are few studies that have documented in detail the long-term outcome of TTTS pregnancies, this study contributes to increase the current knowledge about neurodevelopment of an understudied group, and discusses possible clinical perspectives of early detection.

\section{METHOD}

The research design was an observational, prospective, longitudinal study of monochorionic diamniotic twins who underwent FLC for treatment of TTTS, compared to full-term infants of single-fetus pregnancies, with birth weight appropriate for gestational age during the first year of life. This project was approved by the Research Ethics Committee of the Medical School of the State University of Campinas (UNICAMP) (process nº 935/2011).

Infants were selected using the following inclusion criteria: 1) infants from monochorionic diamniotic twin pregnancies who had TTTS stages I, II, III or IV according to the classification of Quintero et al. ${ }^{11}$ and underwent FLC, composing the study group (TTTS group); 2) the control group was composed of infants born at the Neonatology Service of the Center of Integral Attention to Women's Health - UNICAMP, of single-fetus pregnancies, considered to be in good health allowing them to go home within two days of birth, with gestational age categorized as full-term (37-41 weeks) according to the Capurro method, and showing expected birth weight appropriate for gestational age (between the 10th and 90th percentiles) according to the Alexander method; 3) parents agreed to sign the informed consent; and, 4) infants who were between one month and 12 months of age. Infants who presented with any other malformation unrelated to TTTS were excluded. Considering that we do not have validated Bayley scales, third edition in Brazil, we included a control group of normal infants, to observe the behavior of Brazilian infants with the scale. Our aim was to create a comparison group that might represent Brazilian infants (as much as possible). We considered that we would have a more reliable instrument after that.

All FLC procedures were performed by the same surgeon (CFAP, who had seven years experience in fetoscopic laser surgeries) at the Professor José Aristodemo Pinotti Hospital, from 2009 to 2012, according to the endoscopic laser dichorionization of the placenta procedure. The placental chorionic plate vessels were initially mapped through the amniotic sac of the recipient twin; the vascular equator was identified; a line of ablation of the chorionic plate was created from one edge of the placenta to the other, including the arterio-venous anastomoses and vessels with unknown courses (those crossing the inter-twin membrane from the recipient to the donor side and concealed behind the fixed twin). Caution was taken to preserve the vessels originating from and returning to the same fetus, which were surrounded by this line of ablation. At the end of the photocoagulation process, polyhydramnios fluid was drained through the fetoscopy sheath so that the deepest amniotic fluid pocket was less than $8 \mathrm{~cm}$ deep.

From initial selected sample (40), 33 infants (82.5\%) survived after laser treatment and participated in this study. Development was assessed using the Bayley Scales of Infant and Toddler Development Screening Test, third edition ${ }^{12}$, which included 33 items for testing cognition, 24 items for receptive communication, 24 items for expressive communication, 27 items for fine motor skills and 28 items for gross motor skills.

Each subtest (cognition, receptive language, expressive language, gross motor and fine motor skills) has a starting point consistent with the age or adjusted to the child's age. Every child is given an item score of zero or one. A zero score (0) refers to a child who did not carry out the item or failed to meet the criteria established by the test. The score of one (1) refers to a child who met the criteria established by the test, showing adequate performance on the item.

To start the test, the child is required to achieve a score of one (1) on the first item of his/her starting point previously determined by chronological or adjusted age. The reversal rule is applied when the child is given zero (0) in the first item, requiring the examiner to revert to the previous starting point. The test is completed when the child receives four consecutive zeros.

At the end of the assessment a raw score is obtained for each subtest, which classifies children into three categories: competent (low risk for delay), emerging (requires subsequent reviews) and risk (should be referred for diagnostic assessment) ${ }^{12}$. To perform statistical analyses, the three categories of the Bayley Scale were grouped into two types of responses: appropriate responses (consisting of the competent category), and inadequate responses (comprising emerging and risk categories).

Neurological examination was performed by a pediatric neurologist following our standard protocol ${ }^{13}$. 
The infants were assessed at the Center for Investigation in Pediatrics of UNICAMP from July, 2011 to July, 2013. The infants were evaluated twice, at the age of one to six months for the first evaluation and seven to 12 months for the second evaluation. The adjusted age for prematurity was considered in the neurodevelopmental assessments, using 40 weeks of gestation as a reference. The testers included a developmental neurologist and three physiotherapists. Infants who presented with developmental disorders were referred to a program for habilitation/rehabilitation.

Prenatal, perinatal and postnatal information were obtained through medical records and parent interviews. The following data were recorded: TTTS classification (donor or recipients), TTTS stage (I or II/III/IV), gestational age at surgery, type of delivery (vaginal or cesarean), gender (female or male), fetal growth (SGA or AGA), gestational age at delivery (pre-term or at term), Apgar score at first and fifth minutes ( $<7$ or $\geq 7$ ), cardiorespiratory disease (present or absent), oxygen administration (present or absent), maternal education ( $<9$ or $\geq 9$ ), maternal occupation (work outside or work at home), marital status (without partner or with partner), maternal age, number of children and adults in the home, and economic class according to the Brazilian Association of Research Companies ${ }^{14}$, an instrument of economic segmentation that uses the survey of household characteristics (presence and number of household items and education of the household head) to differentiate the population. The criterion assigns points according to each household characteristic. At the end of the questionnaire, a total score is obtained, which classifies families into eight categories: A1, A2, B1, B2, C1, C2, D, E $\mathrm{E}^{14}$.

Statistical analyses were performed using the Statistical Analysis System (SAS 9.2). The probability level adopted for rejection of the null hypothesis was $\mathrm{p}<0.05$. The data were presented using position and dispersion measurements for numerical variables and frequencies for categorical variables. The comparison of categorical variables between groups was investigated with the Chi-Square or Fisher's Exact Tests. The comparison of paired proportions was examined with McNemar Test. Multiple logistic regression analysis with "stepwise criterion of variable selection" was used to measure the independent effects of prenatal, perinatal and postnatal factors on infant development of TTTS group.

\section{RESULTS}

We present an observational, prospective, longitudinal study of 55 infants (33 infants in the TTTS group and 22 infants in the control group). The mean age of the infants in the first and second assessment were $5.5( \pm 1.4)$ and $9.8( \pm 1.9)$ months respectively.

The descriptive analysis of the characteristics of the two groups is presented in Table 1. In the TTTS group the mean birth weight was 1671 grams $( \pm 689.3)$ and the mean gestational age was 32.4 weeks $( \pm 3.5)$. Following the Quintero classification, 5 children were classified in stage I (15.2\%), 4 in stage II (12.1\%), 18 in stage III (54.5\%) and 6 in stage IV (18.2\%). In the control group, the mean birth weight was 3387.9 grams $( \pm 285.8$ ), and the mean gestational age was 39.2 weeks $( \pm 0.9)$. Considering the family characteristics, in the TTTS and control groups, there was a greater frequency of mothers who had low income (around US\$ 1840 for the TTTS group and US\$ 1068 for the control group).

All infants of the TTTS group underwent neurological examination, which revealed three infants with strabismus (9.1\%), one infant with microcephaly (3.0\%), and six infants with spastic cerebral palsy (18.1\%), four of them with tetraparesis and two with diparesis. Table 2 describes in more detail the situation of each infant with cerebral palsy. Most infants were graded as severe by Quintero classification (III), were small for gestational age, and had Apgar scores at one minute $\leq 7$.

Regarding the assessment with the Bayley Scales, most infants were classified as appropriate for development. In our study the frequency of inappropriate performance in both evaluations for the TTTS group was around $18.2 \%$ for the cognitive domain, $9.1 \%$ for receptive communication, $21.2 \%$ for expressive communication, $24.2 \%$ for fine motor and $24.2 \%$ for gross motor skills. Tables 3 and 4 show comparative analysis between the groups in the first and second assessments respectively. In the first assessment, there were significant differences between the groups only in the cognitive and fine motor domains. In the second assessment, there were significant differences between the groups in all domains (cognitive, receptive and expressive communication, gross and fine motor skills). In both evaluations there were more infants in the TTTS group with inadequate performance in relation to the control group. We found no significant differences in neurodevelopmental outcomes between the first and second assessment of the TTTS group.

Multiple logistic regressions were carried out to measure the association between neurodevelopment and various clinical parameters. The analysis revealed that TTTS classification (OR 6.8, 95\%CI 1.0-44.6, $\mathrm{p}=0.04$ ) and economic class (OR 1.1, 95\%CI 1.0-1.3, p = 0.01) were significantly associated with expressive communication. Infants classified as donors in TTTS had a higher risk of abnormality (6.8 times) than the recipients; and infants whose families had a lower economic score displayed a higher risk of abnormality (each point decreases the risk of abnormality by $16.0 \%)$. Moreover it was found that the cardiorespiratory disease variable (OR 5.6, 95\%CI 1.1-27.5, $\mathrm{p}=0.03$ ) was significantly associated with fine motor function. Infants with cardiorespiratory disease had a higher risk of abnormality (5.6 times) than those without the disease.

The TTTS Quintero stage, gestational age at surgery, type of delivery, gender, fetal growth, gestational age at delivery, Apgar score at first and fifth minutes, oxygen administration, maternal education, maternal occupation, marital status, 
Table 1. Demographic characteristics of the two groups.

\begin{tabular}{|c|c|c|c|c|}
\hline Variables & \multicolumn{2}{|c|}{ TTTS group } & \multicolumn{2}{|c|}{ Control group } \\
\hline TTTS classification - Recipients & \multicolumn{2}{|c|}{$19(57.6 \%)$} & \multicolumn{2}{|c|}{ N/A } \\
\hline Quintero stage - II / III / IV & \multicolumn{2}{|c|}{$28(84.9 \%)$} & \multicolumn{2}{|c|}{$N / A$} \\
\hline Mode of delivery - Cesarean & \multicolumn{2}{|c|}{$32(97.0 \%)$} & \multicolumn{2}{|c|}{$6(27.3 \%)$} \\
\hline Gender - Female & \multicolumn{2}{|c|}{$22(66.7 \%)$} & \multicolumn{2}{|c|}{$15(68.2 \%)$} \\
\hline Fetal growth - AGA & \multicolumn{2}{|c|}{$19(57.6 \%)$} & \multicolumn{2}{|c|}{$22(100 \%)$} \\
\hline Gestational age at birth - Pre-term & \multicolumn{2}{|c|}{$29(87.9 \%)$} & \multicolumn{2}{|c|}{0} \\
\hline \multicolumn{5}{|l|}{ Apgar score } \\
\hline $1 s t-\geq 7$ & \multicolumn{2}{|c|}{$27(81.8 \%)$} & \multicolumn{2}{|c|}{$22(100 \%)$} \\
\hline 5 th $-\geq 7$ & \multicolumn{2}{|c|}{$31(93.9 \%)$} & \multicolumn{2}{|c|}{$22(100 \%)$} \\
\hline \multicolumn{5}{|l|}{ Present } \\
\hline Cardiorespiratory disease & \multicolumn{2}{|c|}{$20(62.5 \%)$} & \multicolumn{2}{|c|}{$5(22.7 \%)$} \\
\hline Oxygen administration & \multicolumn{2}{|c|}{$21(63.6 \%)$} & \multicolumn{2}{|c|}{0} \\
\hline Maternal education (years) $-\geq 9$ & \multicolumn{2}{|c|}{$30(90.9 \%)$} & \multicolumn{2}{|c|}{$17(77.3 \%)$} \\
\hline Maternal occupation - Work at home & \multicolumn{2}{|c|}{$17(51.5 \%)$} & \multicolumn{2}{|c|}{$15(68.2 \%)$} \\
\hline Marital status - with partner & \multicolumn{2}{|c|}{$31(93.9 \%)$} & \multicolumn{2}{|c|}{$16(72.7 \%)$} \\
\hline Numeric variable & Mean & SD & Mean & SD \\
\hline Gestational age at surgery (weeks) & 21.2 & 1.9 & & \\
\hline Maternal age (years) & 29.5 & 6.3 & 25.2 & 7.8 \\
\hline Number of children in the home & 2.5 & 0.9 & 1.4 & 0.6 \\
\hline Number of adults in the home & 2.8 & 1.1 & 3.0 & 1.1 \\
\hline Economic class (score) & 29.9 & 7.9 & 24.6 & 0.6 \\
\hline
\end{tabular}

SD: standard deviation; TTTS: twin-twin transfusion syndrome;AGA: .

Table 2. Characteristics of infants diagnosed with cerebral palsy.

\begin{tabular}{lccccccc}
\hline $\begin{array}{l}\text { Infants with } \\
\text { cerebral palsy }\end{array}$ & $\begin{array}{c}\text { TTTS } \\
\text { classification }\end{array}$ & $\begin{array}{c}\text { Quintero } \\
\text { stage }\end{array}$ & $\begin{array}{c}\text { Gestational age at } \\
\text { surgery (weeks) }\end{array}$ & $\begin{array}{c}\text { Gestational age at } \\
\text { birth (weeks) }\end{array}$ & $\begin{array}{c}\text { Fetal } \\
\text { growth }\end{array}$ & Apgar 1 & Apgar 5 \\
\hline 1 & donor & III & 22.0 & 34.1 & SGA & 8 & 9 \\
2 & donor & III & 19.4 & 28.0 & SGA & 6 & 9 \\
3 & donor & III & 21.1 & 33.4 & SGA & 7 & 8 \\
\hline 4 & recipients & IV & 25.0 & 26.4 & AGA & 6 & 8 \\
\hline 5 & recipients & III & 17.0 & 28.4 & AGA & 8 & 9 \\
\hline 6 & recipients & III & 20.0 & 27.6 & SGA & 7 & 8 \\
\hline
\end{tabular}

TTTS: twin-twin transfusion syndrome; SGA: ;AGA; .

Table 3. Comparative analysis between groups in the first assessment.

\begin{tabular}{|c|c|c|c|c|c|}
\hline \multirow{2}{*}{ Domains } & \multicolumn{2}{|c|}{ TTTS Group } & \multicolumn{2}{|c|}{ Control Group } & \multirow{2}{*}{$p$-value } \\
\hline & Inadequate & Appropriate & Inadequate & Appropriate & \\
\hline Cognition & $10(30.3 \%)$ & $23(69.7 \%)$ & 0 & $22(100 \%)$ & $0.003 *$ \\
\hline Receptive communication & $05(15.1 \%)$ & $28(84.9 \%)$ & $01(4.6 \%)$ & $21(95.4 \%)$ & $0.384^{*}$ \\
\hline Expressive communication & $11(33.3 \%)$ & $22(66.7 \%)$ & $09(40.9 \%)$ & $13(59.1 \%)$ & $0.567 * *$ \\
\hline Gross motor & $14(42.4 \%)$ & $19(57.6 \%)$ & $04(18.2 \%)$ & $18(81.8 \%)$ & $0.060 * *$ \\
\hline Fine motor & $16(48.5 \%)$ & $17(51.5 \%)$ & $02(9.1 \%)$ & $20(90.9 \%)$ & $0.002 * *$ \\
\hline
\end{tabular}

TTTS: twin-twin transfusion syndrome; * Fisher's exact test; ${ }^{* *}$ Chi-Square test. 
Table 4. Comparative analysis between groups in the second assessment.

\begin{tabular}{|c|c|c|c|c|c|}
\hline \multirow{2}{*}{ Domains } & \multicolumn{2}{|c|}{ TTTS Group } & \multicolumn{2}{|c|}{ Control Group } & \multirow{2}{*}{$p$-value } \\
\hline & Inadequate & Appropriate & Inadequate & Appropriate & \\
\hline Cognition & $10(30.3 \%)$ & $23(69.7 \%)$ & 0 & $22(100 \%)$ & $0.003^{*}$ \\
\hline Receptive communication & $05(15.1 \%)$ & $28(84.9 \%)$ & $01(4.6 \%)$ & $21(95.4 \%)$ & $0.384^{*}$ \\
\hline Expressive communication & $11(33.3 \%)$ & $22(66.7 \%)$ & $09(40.9 \%)$ & $13(59.1 \%)$ & $0.567 * *$ \\
\hline Gross motor & $14(42.4 \%)$ & $19(57.6 \%)$ & $04(18.2 \%)$ & $18(81.8 \%)$ & $0.060 * \star$ \\
\hline Fine motor & $16(48.5 \%)$ & $17(51.5 \%)$ & $02(9.1 \%)$ & $20(90.9 \%)$ & $0.002 * *$ \\
\hline
\end{tabular}

TTTS: twin-twin transfusion syndrome; ${ }^{*}$ Fisher's exact test; ${ }^{\star \star}$ Chi-Square test. Domains.

maternal age, number of children and adults at home were not risk factors for neurodevelopmental outcomes.

\section{DISCUSSION}

The focus of the present study was to assess the neurodevelopmental functions (cognition, language and motor function) of survivors of TTTS treated by FLC, and to verify the influence of specific variables on neurodevelopment. We were able to follow up the TTTS group during the first year of life, and compared them to a control group.

Our data showed a high rate of normal neurodevelopmental outcome in a group of infants who were treated for TTTS by FLC. This fact suggests that, although infants with TTTS have a high risk of morbidity, FLC treatment was an effective procedure to allow normal development in most infants ${ }^{8}$. The frequency of inappropriate performance in both evaluations for the TTTS group was around $18.2 \%$ for the cognitive domain, $9.1 \%$ for receptive communication, $21.2 \%$ for expressive communication, $24.2 \%$ for fine motor and $24.2 \%$ for gross motor skills. We also found six infants in our cohort who could be diagnosed as having cerebral palsy.

The neurodevelopmental outcome found in this study is in agreement with other outcome reported previously. The prevalence of cerebral palsy associated with TTTS managed with FLC has been reported to be $3 \%-16 \%$ and the prevalence of neurodevelopmental disabilities to be $12 \%-33 \%^{1,6,7,9,15,16,17}$. The discrepancies in reported rates may partly be due to several methodological differences such as the use of different protocols and criteria for the definition of cerebral injury and neurodevelopmental impairment, including clinical or imaging scans at different ages ${ }^{6,18,19}$.

The comparative analysis between groups showed significant differences at the first and second assessment. There was increased frequency of infants in the TTTS group with inadequate performance in relation to control group. These results are not surprising. Large population-based studies consistently show that the long-term neurodevelopmental outcomes of twins are worse than those of singletons ${ }^{16}$. Language and speech delays are more pronounced in multiples, as are cognitive delays, motor development, behavioral problems and difficulties in parent-child interactions ${ }^{20}$. In multiple gestations, factors such as preeclampsia, TTTS, and the competition between multiple infants for placental nutrient and oxygen delivery seem to place the twins at risk for growth and development problems ${ }^{21}$. TTTS is a well-recognized risk factor for adverse neurodevelopment outcome ${ }^{9}$, and appears to be associated with an increase in long-term cognitive and neuromotor disabilities ${ }^{16}$. The exact mechanism responsible for neurodevelopmental deviation in infants who suffered from TTTS is not clear. The brain injury may result from hemodynamic imbalance and intertwin blood shifts, which lead to hypoxicischemic insults during pregnancy, or from postnatal injury associated with prematurity and low birth weight ${ }^{6}$.

Multiple risk factors can increase the risk of developmental disability, by either additive or multiplicative effects. Genetic factors, nutrition, health, environment in which the children grow up, and opportunities offered by their families are all determinants of child development ${ }^{22-24}$.

It seems that donor and recipient twins with TTTS treated with FLC are equally at risk for cerebral injury and long-term neurodevelopment impairment ${ }^{2,49}$. However, our results showed an independent association between expressive communication disturbance and donor infants. This should be explored in following studies. Similar to our results Tosello ${ }^{1}$ suggested that the risk of neurosensory sequel was significantly related to the status of donor. It is known that donor twins are significantly smaller at birth than recipient twins and remain shorter at two years of age ${ }^{18}$. Lower birth weight has been associated with an increased risk for developmental disturbance ${ }^{25}$. So, this fact may have contributed to worse performance of donor twins in relation to recipient twins.

In the present study, the infants whose families had lower economic income showed a higher risk of expressive communication disturbance. These findings are in agreement with prior research, which has demonstrated strong associations between familial socioeconomic resources and children's health outcome, with especially poor health outcome among disadvantaged youth who experience a concentration of risks ${ }^{26}$. Children from middle and low-income countries face an even greater challenge: in addition to being more susceptible to perinatal problems, these children are also subject to unfavorable household environments, in which 
stimulation and social support are inadequate. This combination of events increases the risk of problems in cognitive, physical, and social development ${ }^{27}$.

Another issue that needs to be addressed is the effect of cardiorespiratory disease on infant development. In the present study infants with cardiorespiratory disease had a higher risk of fine motor disturbance than those without the disease. The abnormal placenta that occurs in cases that develop TTTS contributes to abnormal fetal heart formation, primarily in recipient twins, such as ventricular hypertrophy, atrioventricular valve regurgitation, and abnormal right ventricular or left ventricular function. These cardiac abnormalities can contribute to the poor neurodevelopmental outcome ${ }^{17}$. Likewise, it has been suggested that children who develop chronic lung disease may be developmentally compromised by exposure to hypoxic episodes ${ }^{28}$ and have abnormal motor outcome at one year ${ }^{29}$ and at school-going age ${ }^{30}$. According to the authors, early assessment and motor therapy is recommended for infants with chronic lung disease, because of its effect on motor performance.

The present study has certain limitations that should be taken into account when considering its possible contributions. First, the sample was small; this fact could have influenced the results, at least in part. A larger sample should be considered in future research. Second, we used a non-standard assessment tool for the Brazilian population. However, the Bayley Scales have an overall acceptance, and we included a control group to observe the behavior of Brazilian infants with the scale. Third, we use a control group absolutely no risk, full-term infants of single-fetus pregnancies. Future researches should use a control group of infants from twin pregnancies without TTTS, matched for gestational age.

This study represents one of the few studies addressing the neurodevelopmental functions of monochorionic diamniotic twins who underwent FLC for treatment of TTTS. Our study was conducted during the first year of life and included a control group. We identified three variables that jeopardize the outcome. Infants classified as donors and infants whose families had lower economic income showed higher risk for expressive communication disturbance. Moreover, infants with cardiorespiratory disease had a higher risk for fine motor disturbance.

In conclusion, we were able to establish specific variables ( fetal donor, lower economic income and presence of cardiorespiratory disease) for neurodevelopment impairment in survivors of TTTS after FLC. Although thorough follow-up is recommended in all TTTS survivors, particular attention is required for the high-risk group as defined in this study.

\section{References}

1. Tosello B, Blanc J, Haumonté JB, D’Ercole C, Gire C. Short and medium-term outcomes of live-born twins after fetoscopic laser therapy for twin-twin transfusion syndrome. J Perinat Med. 2014;42(1):99-105. doi:10.1515/jpm-2013-0119

2. Klink JMM, Koopman HM, Oepkes D, Walther FJ, Lopriore E. Long-term neurodevelopmental outcome in monochorionic twins after fetal therapy. Early Hum Dev. 2011;87(9):601-6. doi:10.1016/j.earlhumdev.2011.07.007

3. Maschke C, Diemert A, Hecher K, Bartmann P. Long-term outcome after intrauterine laser treatment for twin-twin transfusion syndrome. Prenat Diagn. 2011;31(7):647-53. doi:10.1002/pd.2797

4. Graeve P, Banek C, Stegmann-Woessner G, Maschke C, Hecher K, Bartmann P. Neurodevelopmental outcome at 6 years of age after intrauterine laser therapy for twin-twin transfusion syndrome. Acta Paediatr. 2012;101(12):1200-5. doi:10.1111/apa.12017

5. Lopriore E, Oepkes D, Walther FJ. Neonatal morbidity in twin-twin transfusion syndrome. Early Hum Dev. 2011;87(9):595-9. doi:10.1016/j.earlhumdev.2011.07.006

6. Spruijt M, Steggerda S, Rath M, Zwet EV, Oepkes D, Walther F et al. Cerebral injury in twin-twin transfusion syndrome treated with fetoscopic laser surgery. Obstet Gynecol. 2012;120(1):15-20. doi:10.1097/AOG.0b013e31825b9841

7. Gray PH, Poulsen L, Gilshenan K, Soong B, Cincotta RB, Gardener G. Neurodevelopmental outcome and risk factors for disability for twin-twin transfusion syndrome treated with laser surgery. Am J Obstet Gynecol. 2011;204(2):159.e1-6. doi:10.1016/j.ajog.2010.08.041

8. Crombleholme T. Central nervous system injury in twin-twin transfusion syndrome: opportunity for improvement? Obstet Gynecol. 2012;120(1):7-8. doi:10.1097/AOG.0b013e31825d5b6c
9. Lopriore E, Ortibus E, Acosta-Rojas R, Le Cessie S, Middeldorp JM, Oepkes D et al. Risk factors for neurodevelopment impairment in twin-twin transfusion syndrome treated with fetoscopic laser surgery. Obstet Gynecol. 2009;113(2 Pt 1):361-6. doi:10.1097/AOG.0b013e318195873

10. Klink JMM, Koopman HM, Zwet EW, Oepkes D, Walther FJ, Lopriore E. Cerebral injury and neurodevelopmental impairment after amnioreduction versus laser surgery in twin-twin transfusion syndrome: a systematic review and meta-analysis. Fetal Diagn Ther. 2013;33(2):81-9. doi:10.1159/000341814

11. Quintero RA, Morales WJ, Allen MH, Bornick PW, Johnson PK, Kruger M. Staging of twin-twin transfusion syndrome. J Perinatol. 1999;19(8):550-5. doi:10.1038/sj.jp.7200292

12. Bayley N. Screening test of bayley scales of infant and toddler development-III. San Antonio: Pearson; 2006.

13. Diament A, Cypel S, Reed UC. Neurologia infantil. 5a ed. São Paulo: Atheneu; 2010.

14. Associação Brasileira de Empresas de Pesquisa - ABEP. Critério de Classificação Econômica Brasil, 2012. http://www.abep.org/novo/ Content.aspx? ContentID=301

15. Wagner MM, Lopriore E, Klumper FJ, Oepkes D, Vandenbussche FPHA, Middeldorp JM. Short- and long-term outcome in stage 1 twin-to-twin transfusion syndrome treated with laser surgery compared with conservative management. Am J Obstet Gynecol. 2009;201(3)286.e1-6. doi:10.1016/j.ajog.2009.05.034

16. Lorenz JM. Neurodevelopmental outcomes of twins. Semin Perinatol. 2012;36(3):201-12. doi:10.1053/j.semperi.2012.02.005

17. Simpson LL. Twin-twin transfusion syndrome. Am J Obstet Gynecol. 2013;208(1):3-18. doi:10.1016/j.ajog.2012.10.880

18. Lopriore E, Middeldorp JM, Sueters M, Oepkes D, Vandenbussche F, Walther FJ. Long-term neurodevelopmental outcome in twin-to-twin 
transfusion syndrome treated with fetoscopic laser surgery. Am J Obstet Gynecol. 2007;196(3):231.e1-4. doi:10.1016/j.ajog.2006.10.906

19. Vries LS, Haastert IC, Benders MJ, Groenendaal F. Myth: cerebral palsy cannot be predicted by neonatal brain imaging. Semin Fetal Neonatal Med. 2011;16(5):279-87. doi:10.1016/j.siny.2011.04.004

20. Sutcliffe AG, Derom C. Follow-up of twins: health, behaviour, speech, language outcomes and implications for parents. Early Hum Dev. 2006;82(6):379-86. doi:10.1016/j.earlhumdev.2006.03.00

21. Garite TJ, Clark RH, Elliott JP, Thorp JA. Twins and triplets: the effect of plurality and growth on neonatal outcome compared with singleton infants. Am J Obstet Gynecol. 2004;191(3):700-7. doi:10.1016/j.ajog.2004.03.040

22. Campos D, Santos DCC, Gonçalves VMG, Goto MMF, Campos-Zanelli TM. Motor performance of infants born small or appropriate for gestational age: a comparative study. Pediatr Phys Ther. 2008;20(4):340-6. doi:10.1097/PEP.0b013e31818a0f78

23. Campos D, Gonçalves VMG, Guerreiro MM, Santos DCC, Goto MMF, Arias AV, et al. Comparison of motor and cognitive performance in infants during the first year of life. Pediatr Phys Ther. 2012;24(2):193-7. doi:10.1097/PEP.0b013e31824d2db7

24. Garibotti G, Comar H, Vasconi C, Giannini G, Pittau C. Child psychomotor development and its relationship with socio-demographic and family stimulation factors in children from Bariloche, Argentina. Arch Argent Pediatr. 2013;111(5):384-90. doi:10.1590/S0325-00752013000500005
25. Class QA, Rickert ME, Lichtenstein P, D’Onofrio BM. Birth weight, physical morbidity, and mortality: a population-based sibling-comparison Study. Am J Epidemiol. 2014;179(5):550-8. doi:10.1093/aje/kwt304

26. Hardie JH, Landale NS. Profiles of risk: maternal health, socioeconomic status, and child health. J Marriage Fam. 2013;75(3):651-66. doi:10.1111/jomf.12021

27. Halpern R, Barros AJ, Matijasevich A, Santos IS, Victora CG, Barros FC. Developmental status at age 12 months according to birth weight and family income: a comparison of two Brazilian birth cohorts. Cad Saude Publica. 2008;24(suppl 3):444-50. doi:10.1590/S0102-311X2008001500010

28. Majnemer A, Riley P, Shevell M, Birnbaum R, Greenstone H, Coates AL. Severe bronchopulmonary dysplasia increases risk for later neurological and motor sequelae in preterm survivors. Dev Med Child Neurol. 2000;42(1):53-60. doi:10.1017/S001216220000013X

29. Zanudin A, Burns Y, Gray PH, Danks M, Poulsen L, Watter P. Perinatal events and motor performance of children born with ELBW and nondisabled. Pediatr Phys Ther. 2013;25(1):30-5 doi:10.1097/PEP.0b013e31827aa424

30. Zanudin A, Gray PH, Burns Y, Danks M, Watter P, Poulsen L. Perinatal factors in non-disabled ELBW school children and later performance. J Paediatr Child Health. 2013;49(1):E62-7. doi:10.1111/jpc.12022 